\title{
Covid-19: Selected NHS patients will be treated with remdesivir
}

\section{Zosia Kmietowicz}

The BMJ

Selected NHS patients in hospital with covid-19 will be given the antiviral drug remdesivir after early trial data suggested that it shortened the time to recovery by about four days, the UK government has said.

Remdesivir, which is manufactured by Gilead and given intravenously, has previously been tested against Ebola and two coronaviruses-Middle East respiratory syndrome and severe acute respiratory syndrome. It is not licensed or approved anywhere in the world.

Last month the US National Institutes of Health (NIH) took the unusual step of reporting interim findings from a randomised controlled trial that began in February involving 1063 patients from several countries. including the US, the UK, and Singapore. ${ }^{1}$ On the same day the Lancet published a trial that found no reduction in deaths with remdesivir. ${ }^{2}$ The NIH said that remdesivir reduced the median time to recovery from 15 to 11 days when compared with placebo, although it failed to say that the trial's primary outcome had been changed after randomisation. The preliminary analysis is now published in the New England Journal of Medicine. ${ }^{3}$

Remdesivir has been made available in the UK through the Early Access to Medicines Scheme (EAMS) after a positive scientific opinion from the Medicines and Healthcare Products Regulatory Agency (MHRA). Similar arrangements have already been made in other countries, including an emergency authorisation from the US Food and Drug Administration and by regulatory authorities in Japan. The EAMS scheme gives patients with life threatening or seriously debilitating conditions access to drugs that have not yet received licensing approval.

"For the time being and due to limited supplies," the government said that any treatment in the UK would be made available to patients meeting certain clinical criteria and guided by expert clinical advice. More details on those criteria were not in the government statement.

Kamran Abbasi, executive editor of The BMJ, said that the early adoption of remdesivir was a triumph of hope, and probably marketing, over data.

"The two major studies of remdesivir to treat hospital patients with covid-19 don't sufficiently support the argument that it shortens illness duration," he said. "The Lancet trial had time to recovery as a secondary outcome and hence can only be suggestive. We also know that preliminary or interim analyses, like the NIH study now published in the New England Journal of Medicine, are inconclusive, and those published in major journals tend to overestimate any benefit. The danger is that the trial is never finished because it becomes hard to recruit patients. We end up with an unanswered research question, and the study is not replicated by other research groups. Meanwhile patients are prescribed a drug with uncertain benefit and even less information on harms."

On 27 May we updated this news story to reflect the Lancet and New England Journal of Medicine articles and to incorporate Kamran Abbasi's comments.

Mahase E. Covid-19: Remdesivir is helpful but not a wonder drug, say researchers. $B M$ 2020;369:m1798. 10.1136/bmj.m1798 32357949

2 Wang Y, Zhang D, Du G, etal . Remdesivir in adults with severe COVID-19: a randomised, double-blind, placebo-controlled, multicentre trial. Lancet 2020;395:1569-78. 10.1016/S0140-6736(20)31022-9 32423584

3 Beigel JH, Tomashek KM, Dodd LE, etal. ACTT-1 Study Group Members. Remdesivir for the treatment of covid-19: preliminary report. N Engl J Med 2020;22. 10.1056/NEJMoa2007764. 32445440

This article is made freely available for use in accordance with BMJ's website terms and conditions for the duration of the covid-19 pandemic or until otherwise determined by BMJ. You may use, download and print the article for any lawful, non-commercial purpose (including text and data mining) provided that all copyright notices and trade marks are retained.

https://bmj.com/coronavirus/usage 